\title{
The Study of Optical Energy Gap, Refractive Index, and Dielectric Constant of Pure and Doped Polyaniline with $\mathrm{HCl}$ and $\mathrm{H}_{2} \mathrm{SO}_{4}$ Acids
}

\author{
Amera G. Baker \\ Department of Physics, Faculty of Science and Health, Koya University, \\ Koya KOY45, Kurdistan Region - F.R. Iraq
}

\begin{abstract}
Polyaniline (PANI) salt in its pure and doped forms find extensive applications in making devices such as polymer light emitting diodes, photovoltaic, sensors, batteries, and super capacitors. PANI salt has been synthesized successfully through chemically oxidative polymerization of aniline in the presence of hydrochloric acid $(\mathrm{HCl})$ and sulfuric acid $\left(\mathrm{H}_{2} \mathrm{SO}_{4}\right)$ using ammonium peroxydisulfate as an oxidizing agent. The absorption spectra of pure PANI salt and its doped state, in $\mathrm{HCl}$ and $\mathrm{H}_{2} \mathrm{SO}_{4}$ media, have been studied in the wavelength range from 200 to $1100 \mathrm{~nm}$ using ultraviolet and visible near infrared spectrophotometer. Tauc's formula, Lambert-Beer's relation, and Fresnel's formula were employed in the MATLAB program to calculate the optical energy gap, refractive index, and dielectric constant. Results showed that doping with $\mathrm{HCl}$ and $\mathrm{H}_{2} \mathrm{SO}_{4}$ acidic mediums caused a reduction in the direct energy gap of the pure PANI from $2.69 \mathrm{eV}$ to $2.42 \mathrm{eV}$ and $2.54 \mathrm{eV}$, respectively. The reduction in optical energy gap is associated with the increase in refractive index. The refractive index (2.92) has a higher value of PANI doped with $\mathrm{HCl}$. Higher refractive index values are for better-structured films.
\end{abstract}

Index Terms - Hydrochloric acid, Optical constants, Polyaniline, Sulfuric acid, Ultraviolet and visible spectroscopy.

\section{INTRODUCTION}

Conducting polymers, especially polyaniline (PANI) is wellknown as an environmentally stable and highly tunable conducting polymer, which can be produced as a bulk powder, cast films, or fibers. This is in conjunction with the feasibility of low-cost, large-scale production makes it an ideal candidate for devices such as supercapacitors (Liao et al., 2018; Du et al., 2017), polymer light emitting diodes (Xu et al., 2016), sensors (Dai et al., 2016), photovoltaic (Gizzie et al., 2015), and batteries (Ma, and Kan, 2013).

ARO-The Scientific Journal of Koya University Volume VII, No.1(2019), Article ID: ARO.10483, 6 pages DOI: $10.14500 /$ aro. 10483

Received 09 January 2019; Accepted 11 May 2019

Regular research paper: Published 30 May 2019

Corresponding author's e-mail: amera.baker@koyauniversity.org Copyright (C) 2019 Amera G. Baker. This is an open-access article distributed under the Creative Commons Attribution License.
The ability of PANI to exist in various forms through acid/ base treatment and oxidation/reduction, either chemically or electrochemically has made PANI the most tunable member of the conducting polymer (Chaqmaqchee, and Baker, 2015; Lu et al., 2011). PANI has a rigid backbone originating from an extended conjugated double bond. The rigid structure of PANI restricts its common usage and results in the insolubility, infusibility, and incompatibility of this material with common polymers (Kenry and Liu, 2018; Bharti et al., 2018). To improve its processability various methods have been tried, and two significant attempts to overcome these drawbacks are chemical modification such as doped PANI and substituted derivatives of PANI, respectively (Liao et al., 2019). The chemically modified PANI not only shows improved processability but also exhibit better conductivity property and anti-corrosion property than pure PANI (Olinga et al., 2000). In the last few years, number of researchers have focused on producing high-quality of PANI by modification of PANI by doping through protonic organic and inorganic acids (Al-Daghman et al., 2016). The solubility and conductivity of PANI can be greatly enhanced by doping through protonic organic acids. Three reasons can possibly explain this phenomenon. First, the protonic organic acids doped into the molecular chain of PANI act as a surfactant, which can improve its solubility. Second, functional groups of the protonic organic acids further improve its solubility. Third, when the protonic organic acids are doped into the PANI molecular chain, it is beneficial to the ionization of charge and meanwhile increases its conductivity (Liao, and $\mathrm{Xu}, 2019$ ). These protonic organic acids commonly contain long alkyl side chains such as camphorsulfonic acid, dodecylbenzene sulfonic acid, p-toluenesulfonic acid, phytic acid, carboxylic acid, acetic acid, and oxalic acid. Since, the size of protonic organic acids is slightly large, causing their diffusion rate slows down. Therefore, more and more researchers turn their attention to protonic inorganic acids due to its size is relatively small, which facilitate its diffusion. Heteropoly acid, as a high-intensity proton acid, can afford protons in the preparation process of PANI, and can also be taken as a solid-state acid in solid-state synthesis reaction (Ladera et al., 2014). (Hassan et al., 2012) studied the a.c 
conductivity of PANI pure and doped with inorganic acids (such as $\mathrm{HCl}$, and $\mathrm{H}_{2} \mathrm{SO}_{4}$ ) at room temperature. They found that the sample doped with $\mathrm{HCl}$ has higher conductivity from the other samples. Furthermore, they found that PANI doped with $\mathrm{H}_{2} \mathrm{SO}_{4}$ has improved the enhanced solubility which dissolvent partially in water. Kulkarni et al., 2004, studied the nanostructures of PANI doped with $\mathrm{HCl}, \mathrm{H}_{2} \mathrm{SO}_{4}$, $\mathrm{HClO}_{4}, \mathrm{HNO}_{3}$, and $\mathrm{H}_{3} \mathrm{PO}_{4}$. The $\mathrm{HClO}_{4}$ doped PANI showed the folded lamellar structure derived from the fibers. Moreover, a greater fraction of the conducting emeraldine salt phase was formed in $\mathrm{HClO}_{4}$ as a protonic acid media. Zhang et al., 2002, studied the nanostructures of PANI doped with inorganic acids such as $\mathrm{HCl}, \mathrm{H}_{2} \mathrm{SO}_{4}, \mathrm{HBF}_{4}$, and $\mathrm{H}_{3} \mathrm{PO}_{4}$. They found that the morphology, size $(150-340 \mathrm{~nm})$, and conductivity $(0.1-10 \mathrm{~S} / \mathrm{cm})$ of the obtained PANI nanostructures mainly relied on the dopant structures and the reaction conditions. Interestingly, the thermal stability of $\mathrm{H}_{3} \mathrm{PO}_{4}$ doped PANI was found to be improved compared to other acids doped PANI. Gong et al., 2002, described a novel solid-state synthesis method to prepare $\mathrm{H}_{4} \mathrm{SiW}_{12} \mathrm{O}_{40}$ doped PANI. The conductivity property and fluorescence property of the $\mathrm{H}_{4} \mathrm{SiW}_{12} \mathrm{O}_{40}$ doped PANI were found to be excellent. In this work, PANI salt has been synthesized through chemically oxidative polymerization of aniline in the presence of hydrochloric acid $(\mathrm{HCl})$, and sulfuric acid $\left(\mathrm{H}_{2} \mathrm{SO}_{4}\right)$ using ammonium peroxydisulfate (APS) as an oxidizing agent at room temperature. The synthesis of pure PANI and in its doped state, in $\mathrm{HCl}(\mathrm{PANI}-\mathrm{HCl})$ and $\mathrm{H}_{2} \mathrm{SO}_{4}$ $\left(\mathrm{PANI}-\mathrm{H}_{2} \mathrm{SO}_{4}\right)$ media were studied and characterized in terms of absorption properties, optical energy gap, refractive index, and dielectric constant. The purpose of this work is to synthesis the easiest and cheapest method with a high quality of PANI for electronics device applications.

\section{Materials AND Methods}

\section{A. Materials}

The chemicals used in the preparation of PANI are aniline hydrochloric $\left(\mathrm{C}_{6} \mathrm{H}_{5} \mathrm{NH}_{2} \mathrm{HCl}\right)$, ammonium persulfate $\left(\mathrm{NH}_{4}\right)_{2} \mathrm{~S}_{2} \mathrm{O}_{8}, \mathrm{HCl}, \mathrm{H}_{2} \mathrm{SO}_{4}$, acetone, and dimethylformamide (DMF) are of high purity (>99\%), which their supplier companies are Hopkin and Williams (UK) and BDH (Middle East LLC) were obtained from the Chemistry Department, College of Science, University of Baghdad.

\section{B. Synthesis of Pure and Doped PANI}

PANI salt has been synthesized through chemically oxidative polymerization of aniline in the presence of $\mathrm{HCl}$ and $\mathrm{H}_{2} \mathrm{SO}_{4}$ using APS as an oxidizing agent (Ninh et al., 2016; Hassan et al., 2012). The aniline hydrochloride and APS solutions were prepared by mixing $(0.2 \mathrm{M})$ aniline hydrochloride with $(0.25 \mathrm{M})$ APS in an aqueous medium. The pure sample was prepared in distilled water and the doped samples with (2) molarities of $\mathrm{HCl}$ and $\mathrm{H}_{2} \mathrm{SO}_{4}$ in aqueous solution. Three- necked round-bottomed flask equipped with a thermometer. Electromagnetic stirrer and condenser were used to polymerize PANI. To prepared sample doped with (2 M), aniline hydrochloride in $(1 \mathrm{M})$ aqueous solution in a volumetric flask to $(50 \mathrm{ml})$ of solution, ammonium pexroydisulfate is similarly dissolved in $(1 \mathrm{M}) \mathrm{HCl}$ also to $50 \mathrm{ml}$ of solution, both solutions are mixed at room temperature in a rounder, and gentle stirring to polymerize the mixture, and left the rest to the next day. The (PANI) precipitate is collected on a filter and washed with 3 times $(100 \mathrm{ml})$ of $0.2 \mathrm{M} \mathrm{HCl}$, and 150 $\mathrm{M}$ of acetone. PANI (emeraldine salt) hydrochloride powder was dried in air for $1 \mathrm{~h}$ than in the vacuum oven at $80^{\circ} \mathrm{C}$ for $6 \mathrm{~h}$; the powder was thoroughly grounded in a mortar to obtain very fine particles. In a similar way, PANI has been doped with $\mathrm{H}_{2} \mathrm{SO}_{4}$ acid; Figs. 1 and 2 (Al-Daghman et al., 2016; Stejskal, and Polyaniline, 2002). The standard solution cast technique was used to prepare the pure and doped PANI films. The PANI solution was prepared by weighted $0.1 \mathrm{~g}$ of PANI salt and dissolved in $10 \mathrm{ml}$ of DMF and stirring for $3 \mathrm{~h}$. The solutions were then cast into different clean and dry dishes and allowed to evaporate at room temperature until solvent-free films were obtained.

\section{Ultraviolet and visible (UV-Vis) Spectroscopy}

UV-Vis spectrophotometer model UV/1601 manufactured by Shimadzu Co. (Japan) was carried out in the Chemistry Department, College of Science, University of Baghdad (Manual, 1994; Robert et al., 2005). UV-Vis spectroscopy is a reliable and accurate analytical laboratory assessment procedure that allows for both qualitative and quantitative analysis of a substance. Specifically, UV-Vis spectroscopy probes the electronic transitions of molecules as they absorb light in the UV and visible regions of the electromagnetic
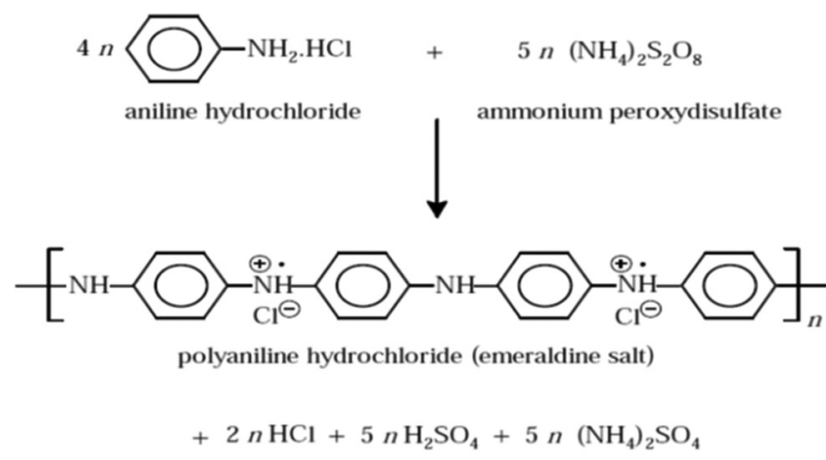

Fig. 1. Oxidation of aniline hydrochloride with ammonium peroxydisulfate yields polyaniline hydrochloride.
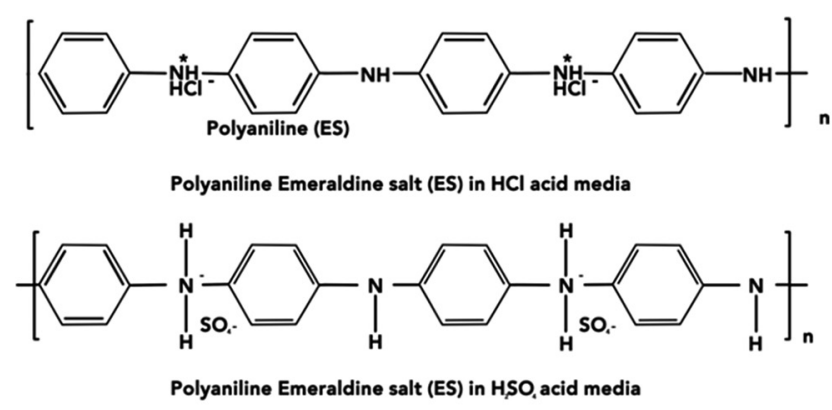

Fig. 2. Protonic acid media doping of polyaniline (PANI) (PANIemeraldine salt). 
radiation (Schymanski et al., 2014). The absorption spectra of the synthesized pure and doped PANI were recorded over a wavelength range of $200-1100 \mathrm{~nm}$. The MATLAB program was used, and Tauc's formula, Beer-Lambert's relation, and Fresnel's formula were employed in the program to calculate the absorption coefficient and the optical constants.

\section{RESULTS AND Discussions}

\section{A. Absorbance Spectra of Pure and Doped Samples}

Fig. 3 shows the UV-visible absorption spectra at the range 200-1100 nm of pure and doped PANI with $\mathrm{HCl}$ and $\mathrm{H}_{2} \mathrm{SO}_{4}$. The absorption peaks occur at 200 and $553 \mathrm{~nm}$ of pure PANI assigned to $\pi \rightarrow \pi^{*}$ electronic transitions related to the benzenoid form of PANI and polaron $\rightarrow \pi^{*}$ electronic transitions related to the quinoid rings of PANI, respectively (Melad, and Jarur, 2016). The absorption spectra of doped PANI with $\mathrm{HCl}$ showed two peaks around $200 \mathrm{~nm}$ and $870 \mathrm{~nm}$ assigned to $\pi \rightarrow \pi^{*}$ electronic transitions and $\pi \rightarrow$ polaron electronic transitions, respectively. The absorption spectra of doped PANI with $\mathrm{H}_{2} \mathrm{SO}_{4}$ showed three peaks around $200 \mathrm{~nm}$, $271 \mathrm{~nm}$, and $885 \mathrm{~nm}$ assigned to $\pi \rightarrow \pi^{*}$ electronic transitions, polaron $\rightarrow \pi^{*}$ electronic transitions, and $\pi \rightarrow$ polaron electronic transitions, respectively (Hassan, 2013; Yin, and Ruckenstein, 2000). This confirms the polaron band formation in the band gap of the polymer on of protonic acid doping (Al-Daghman et al., 2016; Varma et al., 2012). In general, PANI-HCl exhibited the best optical absorbance in the UV, visible and Near Infrared regions among the other samples.

\section{B. Optical Band Gap}

Optical absorption spectra constitute one of the most important means to determine the optical energy gap $\left(\mathrm{E}_{\mathrm{g}}\right)$ of organic and inorganic semiconductors (Muhammad et al., 2010). Energy gap is called band gap which is of fundamental importance because the energy gap determines the electrical conductivity and optical absorption character of the PANI. The absorption coefficient $(\alpha)$, at the corresponding wavelengths, is calculated using the BeerLambert's relation: $\alpha=2.303 \mathrm{~A} / 1$ where 1 is the path length and $\mathrm{A}$ is the absorbance (Hassan, 2013). Fig. 4 shows the absorption coefficient as a function of the wavelength of pure and doped PANI. The photon absorption in many amorphous materials is found to obey the Tauc relation (Abdulla, and Abbo, 2012; Muhammad et al., 2011), which is of the form:

$$
A h v=B\left(h v-E_{g}\right)^{m}
$$

Where $h v$ is the energy of the incident photon, $E_{g}$ is the optical energy band gap, $B$ is a constant known as the disorder parameter which is nearly independent of photon energy parameter, and $m$ is the power coefficient with the value that is determined by the type of possible electronic transitions. For the direct and indirect allowed transition $=1 / 2$ or 2 , respectively (Gupta et al., 2010). For high absorption coefficient $\alpha>10^{3} \mathrm{~cm}^{-1}$ that refers to the direct transition (Zeadan et al., 2009; Ali et al., 2008). The index $n=1 / 2$ represents the directly allowed transition energy gap. To determine the value of the energy gap, graphs of $(\alpha h v)^{2}$ against $h v$ were plotted, as shown in Fig. 5. Extrapolation of this plot for $(\alpha h v)^{2}=0$ gives the value of $\mathrm{E}_{\mathrm{g}}$ (Muhammad et al., 2017). The value of the optical direct transition energies

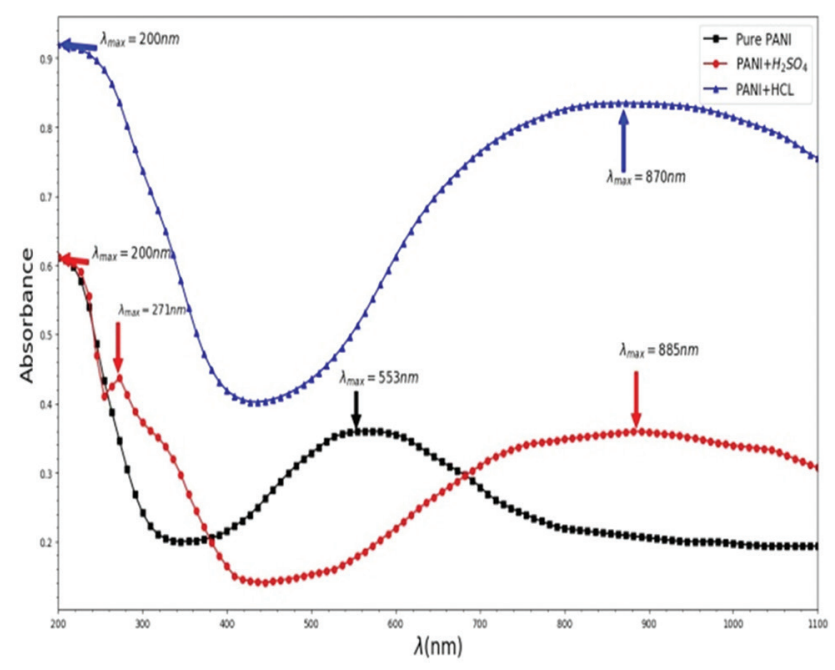

Fig. 3. Ultraviolet-visible absorbance spectra of pure and polyaniline doped with hydrochloric acid and sulfuric acid.

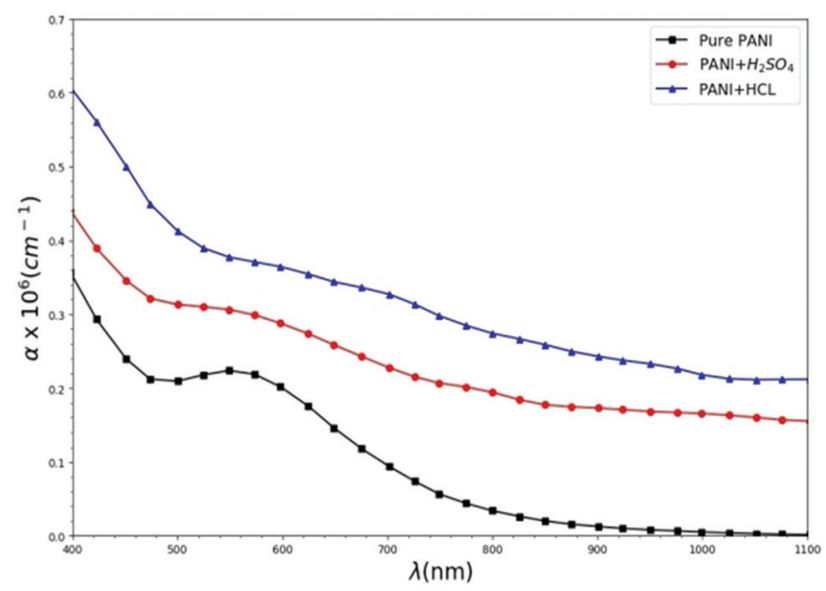

Fig. 4. Absorption coefficient as a function of the wavelength of pure and doped polyaniline with hydrochloric acid and sulfuric acid.

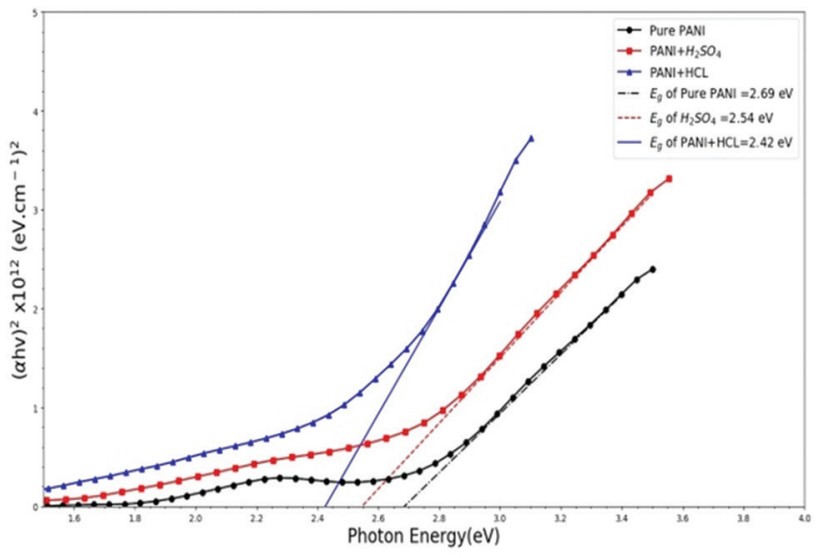

Fig. 5. Direct allowed transition energy of pure polyaniline (PANI) and doped PANI with hydrochloric acid and sulfuric acid. 
obtained from Fig. 5 is $2.69 \mathrm{eV}, 2.42 \mathrm{eV}$, and $2.54 \mathrm{eV}$ of pure and doped PANI with $\mathrm{HCl}$, and $\mathrm{H}_{2} \mathrm{So}_{4}$, respectively. The reduction in the optical band gap is probably due to the modification of the polymer structure (Mathai et al., 2002). The energy gap determines the electrical conductivity and optical absorption character of the PANI. The reduction in the optical band gap to $2.42 \mathrm{eV}$ due to the dimensions of resulting ions, which play an important role in the process of diffusion, it is known that acids are compounds that dissociate in water, only to give positive hydrogen ions and negative ions of the acid residue. In doping PANI with $\mathrm{HCl}$, dissociation to cations and anions takes place: $\mathrm{HCl} \mathrm{H}^{+}+\mathrm{Cl}^{-}$ while in doping with $\mathrm{H}_{2} \mathrm{SO}_{4}$, the dissociation is:

$$
\mathrm{H}_{2} \mathrm{SO}_{4} \rightarrow 2 \mathrm{H}^{+}+\mathrm{SO}_{4}^{-2}
$$

In both cases, positive hydrogen cations are formed. The difference is in the negative anions that are in the first case the anions of non-metal $\left(\mathrm{Cl}^{-1}\right)$, and in the second case the anions $\left(\mathrm{SO}_{4}^{-2}\right)$ are composed as molecules, but the particle is negatively charged (Gazdic et al., 2016).

\section{Refractive Index and Optical Dielectric Constant}

The refractive index $(n)$ is a fundamental optical property of polymers that are directly related to other optical, electrical, and magnetic properties, and also of interest to those studying the physical, chemical, and molecular properties of polymers by optical techniques. The optical properties of the samples can be characterized by the complex refractive index. The complex refractive index is expressed as $n=n(\omega)+i k(\omega)$ where $n(\omega)$ is the real part and $k(\omega)$ is the imaginary part of refractive index. The refractive index, n, can be estimated, using the Fresnel formulae as follows (Muhammad et al., 2017; Aziz et al., 2017; Hassan, 2013):

$$
n=\left[\frac{4 R}{(R-1)^{2}}-k^{2}\right]^{1 / 2}-\frac{(R+1)}{(R-1)}
$$

Where $R$ is the reflectivity and $k=\alpha \lambda / 4 \pi$ is the extinction coefficient. The extinction coefficient $\mathrm{k}$ describes the properties of the material with respect to light of a given wavelength and indicates the absorption changes when the electromagnetic wave propagates through the material (AlTememee et al., 2012). The values of reflective index $n$ as a function of the wavelength of pure and doped PANI with $\mathrm{HCl}$, and $\mathrm{H}_{2} \mathrm{SO}_{4}$ is shown in Fig. 6. It is observed that the refractive index decreases with the increase of the wavelength. The value of the refractive index at the wavelength $800 \mathrm{~nm}$ is $1.14,2.92$, and 1.82 of pure and doped PANI with HCL, and $\mathrm{H}_{2} \mathrm{So}_{4}$, respectively. The increase in the reflective index may be attributed to higher packing density and change in crystalline structure also by increasing the $\mathrm{C}-\mathrm{H}$ bonds (Nahida, and Marwa, 2011). Higher refractive index values are for better-structured films (Al-Tememee et al., 2012). The dielectric constant $(\varepsilon)$ consists of a real part $\left(\varepsilon_{r}\right)$ and an imaginary part $\left(\varepsilon_{i}\right)$, which depend on the frequency of the electromagnetic wave. $\varepsilon_{r}$ is the real part associated with the term that shows how much it will slow down the speed of light in the material. $\varepsilon_{i}$ is the imaginary part of the dielectric constant, which shows how a dielectric absorbs energy from an electric field due to dipole motion. The imaginary part of the dielectric constant was determined by the following relations (Ahmed et al., 2009; Aqili et al., 2000):

$$
\begin{aligned}
\varepsilon_{r} & =n^{2}-k^{2} \\
\varepsilon_{I} & =2 n k
\end{aligned}
$$

The real part of dielectric constant is related to the dispersion, and the imaginary part represents the dissipative rate of electromagnetic wave propagation in the medium. The real and imaginary parts of the dielectric constant as a function of wavelength are shown in Figs. 7 and 8 of pure and doped PANI with $\mathrm{HCl}$ and $\mathrm{H}_{2} \mathrm{SO}_{4}$. The variation of $\varepsilon_{r}$ depends on the values of $n^{2}$ as a result of small values of $k^{2}$ in comparison with $n^{2}\left(\varepsilon_{r}=n^{2}\right)$, whereas $\varepsilon_{i}$ mainly depends on the $k$ values which are related to the variation of absorption coefficient (Faramarzpour et al., 2008). From Fig. 7, the value of $\varepsilon_{r}$ at the wavelength $800 \mathrm{~nm}$ is $1.33,8.70$, and 3.29 of pure and doped PANI with $\mathrm{HCL}$, and $\mathrm{H}_{2} \mathrm{SO}_{4}$, respectively. The values of the optical properties of pure and doped PANI with $\mathrm{HCL}$ and $\mathrm{H}_{2} \mathrm{So}_{4}$ are presented in Table I. The reduction in optical band gap is associated with the increase in refractive index. The decrease in the optical band gap (Table I) can be related to an increase in optical dielectric constant. An increase in an optical dielectric constant means

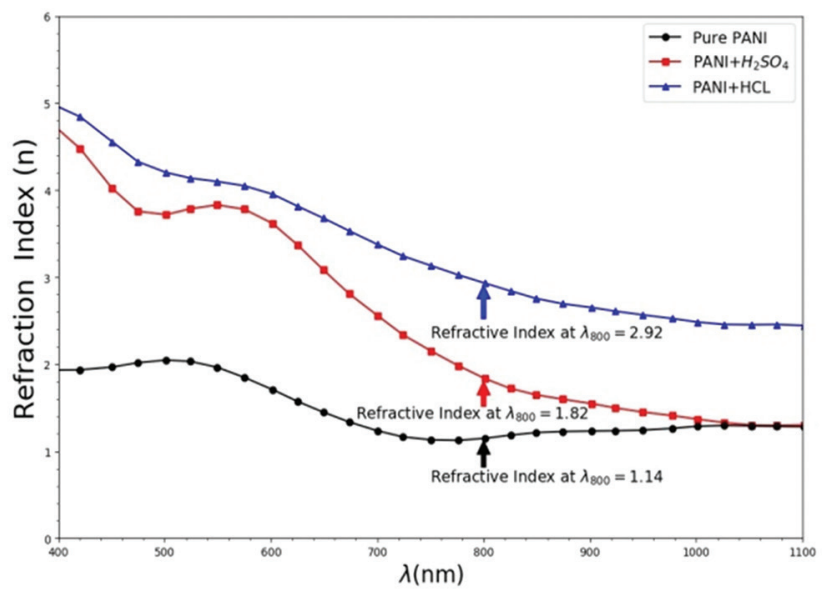

Fig. 6. Index of refraction as a function of the wavelength of pure polyaniline and doped with hydrochloric acid and sulfuric acid.

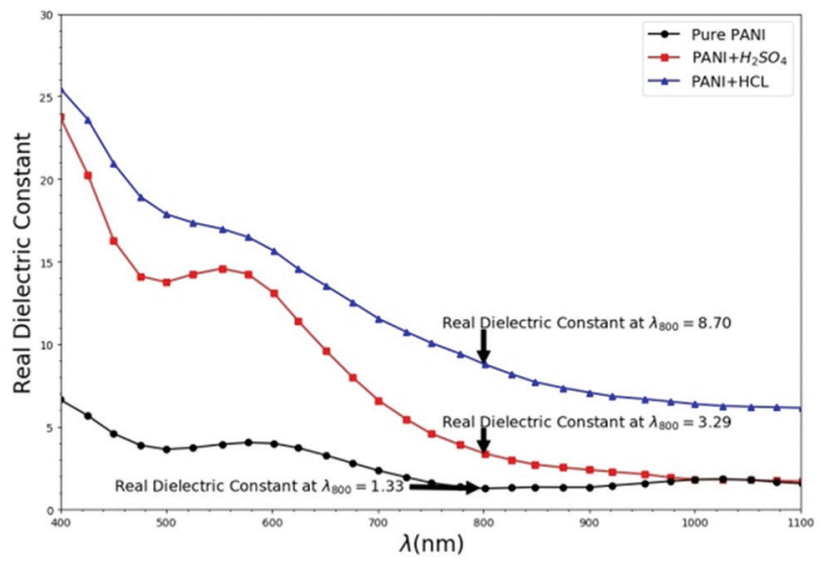

Fig. 7. Real dielectric constant versus wavelength of pure polyaniline and doped with hydrochloric acid and sulfuric acid. 


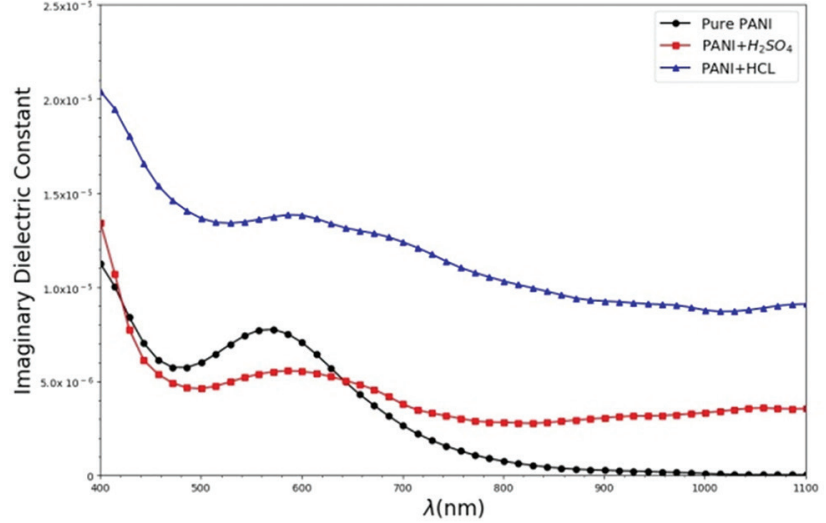

Fig. 8. Imaginary dielectric constant versus of wavelength of pure and doped polyaniline with hydrochloric acid and sulfuric acid.

TABLE I

The Optical Properties of Pure and PANI Doped with HCL and $\mathrm{H}_{2} \mathrm{SO}_{4}$

\begin{tabular}{lcccccc}
\hline \hline Sample & Absorbance & $\lambda$ & $\varepsilon_{g}$ & $\begin{array}{c}n \text { from Fig.6 at } \\
800 \mathrm{~nm}\end{array}$ & $\begin{array}{c}\varepsilon_{r} \text { from Fig.7 at } \\
800 \mathrm{~nm}\end{array}$ & $\varepsilon_{r}=n^{2}$ \\
\hline Pure PANI & 0.61 & 200 & 2.699 & 1.14 & 1.33 & 1.29 \\
& 0.36 & 553 & & & \\
$-\mathrm{HCl}$ & 0.92 & 200 & 2.42 & 2.92 & 8.70 & 8.52 \\
& 0.83 & 870 & & & & \\
PANI- $\mathrm{H}_{2} \mathrm{SO}_{4}$ & 0.61 & 200 & 2.54 & 1.82 & 3.29 & 3.31 \\
& 0.44 & 271 & & & & \\
& 0.36 & 885 & & & & \\
&
\end{tabular}

PANI: Polyaniline, $\mathrm{HCl}$ : Hydrochloric acid, $\mathrm{H}_{2} \mathrm{SO}_{4}$ : Sulfuric acid.

the introduction of more charge carriers to the host material and thus an increase in the density of states.

\section{CONCLUSION}

PANI salt has been synthesized via chemically oxidative polymerization of aniline in the presence of $\mathrm{HCl}$ and $\mathrm{H}_{2} \mathrm{SO}_{4}$ using APS as an oxidizing agent at room temperature. PANI salts were characterized using UV-Vis spectroscopy to investigate the variations in the optical properties. Doping with $\mathrm{HCl}$ and $\mathrm{H}_{2} \mathrm{SO}_{4}$ reduced the direct band gap of the pure PANI from $2.69 \mathrm{eV}$ to $2.42 \mathrm{eV}$ and $2.54 \mathrm{eV}$. The reduction in optical band gap is associated with the increase in refractive index. The refractive index has a higher value of PANI doped with $\mathrm{HCl}$ (2.92). Higher refractive index values are for better-structured films.

\section{REFERENCES}

Abdulla, H.S., and Abbo, A.I., 2012. Optical and electrical properties of thin films of polyaniline and polypyrrole. International. Journal of Electrochemical Science, 7, pp.10666-10678.

Ahmed, N.M., Sauli, Z., Hashim, U., and Al-Douri, Y., 2009. Investigation of the absorption coefficient, refractive index, energy band gap and film thickness for A10. $11 \mathrm{Ga} 0.89 \mathrm{~N}, \mathrm{~A} 10.03 \mathrm{Ga}$. International Journal of Nanoelectronics and Materials, 2, pp.189-195.

Al-Daghman, A.N.J., Ibrahim, K., Ahmed, N.M., and Al-Messiere, M.A., 2016. Effect of doping by stronger ions salt on the microstructure of conductive polyaniline-ES: Structure and properties. Journal of Optoelectronics and
Biomedical Materials, 8(4), pp.175-183.

Ali, Z.R., Zeadan, A.M., and Ziadan, K.M., 2008. The optical properties of polyaniline blend with poly-methal-methacrylate as conducting polymers alloys (PAni/PMMA). Basrah Journal of Science, 26(1), pp.12-17.

Al-Tememee, N.A., Saeed, N.M., Al-Dujayli, S.M., and Chiad, B.T., 2012. The effect of zn concentration on the optical properties of Cd10-xZnxS films for solar cells applications. Advances in Materials Physics and Chemistry, 2(2), p.69.

Aqili, A.K., Ali, Z., and Maqsood, A., 2000. Optical and structural properties of two-sourced evaporated ZnTe thin films. Applied Surface Science, 167(1-2), pp.1-11.

Aziz, S.B., Rasheed, M.A., and Ahmed, H.M., 2017. Synthesis of polymer nanocomposites based on [Methyl cellulose](1-x): (CuS) $\mathrm{x}(0.02 \mathrm{M} \leq \mathrm{x} \leq 0.08$ M) with desired optical band gaps. Polymers, 9(6), p.194.

Bharti, M., Singh, A., Samanta, S., and Aswal, D.K., 2018. Conductive polymers for thermoelectric power generation. Progress in Materials Science, 93, pp.270-310.

Chaqmaqchee, F.A.I., and Baker, A.G., 2015. Study and characterization of polyaniline at various doping of $\mathrm{LiCl}$ wt.\% using electrical measurements and XRF analysis. Journal of Research Updates in Polymer Science, 4(4), p.188.

Dai, H., Wang, N., Wang, D., Ma, H., and Lin, M., 2016. An electrochemical sensor based on phytic acid functionalized polypyrrole/graphene oxide nanocomposites for simultaneous determination of $\mathrm{Cd}$ (II) and $\mathrm{Pb}$ (II). Chemical Engineering Journal, 299, pp.150-155.

Du, X., Zhang, Z., Liu, W., and Deng, Y., 2017. Nanocellulose-based conductive materials and their emerging applications in energy devices a review. Nano Energy, 35, pp.299-320.

Faramarzpour, N., Deen, M.J., Shirani, S. and Fang, Q., 2008. Fully integrated single photon avalanche diode detector in standard CMOS 0.18-\$ $\backslash \mathrm{mu} \$ \mathrm{~m}$ Technology. IEEE Transactions on Electron Devices, 55(3), pp.760-767.

Gazdic, I., Modric-Šahbazovic, A., and Sulejmanovic, S., 2016. Analysis of specific electric conductivity of thin films of polyaniline doped with sulfuric and hydrochloric acid. TEM Journal, 5(1), p.38.

Gizzie, E.A., Niezgoda, J.S., Robinson, M.T., Harris, A.G., Jennings, G.K., Rosenthal, S.J., and Cliffel, D.E., 2015. Photosystem I-polyaniline/TiO 2 solidstate solar cells: Simple devices for biohybrid solar energy conversion. Energy and Environmental Science, 8(12), pp.3572-3576.

Gong, J., Cui, X.J., Xie, Z.W., Wang, S.G., and Qu, L.Y., 2002. The solidstate synthesis of polyaniline/ $\mathrm{H}_{4} \mathrm{SiW}_{12} \mathrm{O}_{40}$ materials. Synthetic Metals, 129(2), pp.187-192.

Gupta, K., Jana, P.C., and Meikap, A.K., 2010. Optical and electrical transport properties of polyaniline silver nanocomposite. Synthetic Metals, 160(13-14), pp.1566-1573.

Hassan, S., Ghareeb, B.A., and Jafaar, H.I., 2012. AC electrical condutivity for polyaniline prepared in different acidic medium. International Journal of Basic and Applied Science, 1, pp.352-362.

Hassan, S.M., 2013. Optical properties of prepared polyaniline and polymethylmethacrylate blends. International Journal of Application or Innovation in Engineering and Management, 2(9), pp.232-235.

Kenry and Liu, B., 2018. Recent advances in biodegradable conducting polymers and their biomedical applications. Biomacromolecules, 19(6), pp.1783-1803.

Kulkarni, M.V., Viswanath, A.K., Marimuthu, R., and Seth, T., 2004. Synthesis and characterization of polyaniline doped with organic acids. Journal of Polymer Science Part A: Polymer Chemistry, 42(8), pp.2043-2049.

Ladera, R.M., Fierro, J.L.G., Ojeda, M., and Rojas, S., 2014. TiO2-supported heteropoly acids for low-temperature synthesis of dimethyl ether from methanol. Journal of Catalysis, 312, pp.195-203.

Liao, G., Li, Q., and Xu, Z., 2019. The chemical modification of polyaniline with enhanced properties: A review. Progress in Organic Coatings, 126, pp.35-43. 
Liao, G., Li, Q., Zhao, W., Pang, Q., Gao, H., and Xu, Z., 2018. In situ construction of novel silver nanoparticle decorated polymeric spheres as highly active and stable catalysts for reduction of methylene blue dye. Applied Catalysis A: General, 549, pp.102-111.

Lu, X., Zhang, W., Wang, C., Wen, T.C., and Wei, Y., 2011. One-dimensional conducting polymer nanocomposites: Synthesis, properties and applications. Progress in Polymer Science, 36(5), pp.671-712.

Ma, Z., and Kan, J., 2013. Study of cylindrical Zn/PANI secondary batteries with the electrolyte containing alkylimidazolium ionic liquid. Synthetic Metals, 174, pp.58-62.

Manual, I., 1994. Shimadzu Corporation. Analytical Instrument Plant, Kyoto, Japan.

Mathai, C.J., Saravanan, S., Anantharaman, M.R., Venkitachalam, S., and Jayalekshmi, S., 2002. Effect of iodine doping on the bandgap of plasma polymerized aniline thin films. Journal of Physics D: Applied Physics, 35(17), p.2206.

Melad, O., and Jarur, M., 2016. Studies on the effect of doping agent on the structure of polyaniline. Chemistry and Chemical Technology, 10(1), pp.41-44.

Muhammad, F.F., and Sulaiman, K., 2011. Utilizing a simple and reliable method to investigate the optical functions of small molecular organic films Alq3 and Gaq3 as examples. Measurement, 44(8), pp.1468-1474.

Muhammad, F.F., Hapip, A.I.A., and Sulaiman, K., 2010. Study of optoelectronic energy bands and molecular energy levels of tris (8-hydroxyquinolinate) gallium and aluminum organometallic materials from their spectroscopic and electrochemical analysis. Journal of Organometallic Chemistry, 695(23), pp.2526-2531.

Muhammad, F.F., Yahya, M.Y., Aziz, F., Rasheed, M.A., and Sulaiman, K., 2017. Tuning the extinction coefficient, refractive index, dielectric constant and optical conductivity of Gaq3 films for the application of OLED displays technology. Journal of Materials Science: Materials in Electronics, 28(19), pp.14777-14786.
Ninh, D.H., Thao, T.T., Long, P.D. and Dinh, N.N., 2016. Characterization of electrochromic properties of polyaniline thin films electropolymerized in $\mathrm{H}_{2} \mathrm{SO}_{4}$ Solution. Open Journal of Organic Polymer Materials, 6(01), pp.30.

Nahida, J.H., and Marwa, R.F., 2011. Study of the optical constants of the PMMA/ PC blends. AIP Conference Proceedings, 1400(1), pp.585-595.

Olinga, T.E., Fraysse, J., Travers, J.P., Dufresne, A., and Pron, A., 2000. Highly conducting and solution-processable polyaniline obtained via protonation with a new sulfonic acid containing plasticizing functional groups. Macromolecules, 33(6), pp.2107-2113.

Robert, M.S., Francis, X.W., and David, J.K., 2005. Spectrometric Identification of Organic Compounds. $7^{\text {th }}$ ed. John Wiley and Sons, Inc., Hoboken, p.106.

Schymanski, E.L., Jeon, J., Gulde, R., Fenner, K., Ruff, M., Singer, H.P., and Hollender, J., 2014. Identifying small molecules via high resolution mass spectrometry: Communicating confidence. Environmental Science and Technology, 48(4), pp.2097-2098.

Stejskal, J., and Polyaniline, G.R.G., 2002. Preparation of a conducting polymer (IUPAC technical report). Pure and Applied Chemistry, 74(5), pp.857-867.

Varma, S.J., Xavier, F., Varghese, S., and Jayalekshmi, S., 2012. Synthesis and studies of exceptionally crystalline polyaniline thin films. Polymer International, 61(5), pp.743-748.

Xu, R.P., Li, Y.Q., and Tang, J.X., 2016. Recent advances in flexible organic light-emitting diodes. Journal of Materials Chemistry C, 4(39), pp.9116-9142.

Yin, W., and Ruckenstein, E., 2000. Soluble polyaniline co-doped with dodecyl benzene sulfonic acid and hydrochloric acid. Synthetic Metals, 108(1), pp.39-46.

Zeadan, K.M., Talab, R.A., and Satar, J., 2009. The optical properties of polyaniline (PAni) prepared by chemical method. Journal of Kufa Physics, 1(2), pp.1-11.

Zhang, Z., Wei, Z., and Wan, M., 2002. Nanostructures of polyaniline doped with inorganic acids. Macromolecules, 35(15), pp.5937-5942. 